\title{
The weighted version of the handshaking lemma with an application
}

Baoyindureng $\mathrm{Wu}^{*}$

\section{"Correspondence:}

wubaoyin@hotmail.com

College of Mathematics and System

Sciences, Xinjiang University,

Urumqi, Xinjiang 830046, P.R. China

\begin{abstract}
The purpose of the present note is to establish the weighted version of the handshaking lemma with an application to chemical graph theory.
\end{abstract}

MSC: $05 C 90$

Keywords: the handshaking lemma; Randić index

\section{Introduction}

The graphs under consideration are finite, but may have loops and parallel edges. Let $G=$ $(V(G), E(G))$ be a graph. For a vertex $v \in V(G), d(v)$ denotes the degree of the vertex $v$, that is, the number of edges incident with $v$, where a loop incident with $v$ is counted twice. We say that $|V(G)|$ and $|E(G)|$ are the order and size of $G$, respectively.

Around the middle of the 20th century theoretical chemists recognized that useful information on the dependence of various properties of organic substances on molecular structure can be obtained by examining pertinently constructed invariants of underlying molecular graphs. Eventually, graph invariants that are useful for chemical purpose, were named 'topological indices' or 'molecular structure-descriptors'. A large number of various 'topological indices' was proposed and studied in chemical literature [1].

In 1975, Randić [2] introduced the so-called 'branching index'. The branching index of a graph $G$ is now widely known as the Randić index of $G$, defined as

$$
R(G)=\sum_{u v \in E(G)} \frac{1}{\sqrt{d(u) d(v)}} .
$$

We refer to the monograph [3] and the survey article [4] for the various results on the Randić index, and to [5-11] for some recent results concerning Randić index of graphs. Bollobás and Erdős [12] showed that for a graph of order $n$ without isolated vertices, $R(G) \geq \sqrt{n-1}$ with equality if and only if $G$ is the star $K_{1, n-1}$. The sharp upper bound for the Randić index of graphs of order $n$ is due to Fajtlowicz [13].

Theorem 1.1 (Fajtlowicz [13]) For a graph G of order n,

$$
R(G) \leq \frac{n}{2}
$$

with equality if and only if every component of $G$ is regular and $G$ has no isolated vertices. 
The proof of Fajtlowicz is based on Cauchy's inequality. Caporossi et al. [14] gave an alternative proof of Theorem 1.1 by using an equivalent formulation for the Randić index of a graph:

$$
R(G)=\frac{n-n_{0}}{2}-\sum_{u v \in E(G)} \frac{1}{2}\left(\frac{1}{\sqrt{d(u)}}-\frac{1}{\sqrt{d(u)}}\right)^{2},
$$

where $n_{0}$ is the number of isolated vertices in G. Using linear programming, Pavlović and Gutman [15] gave another proof of Theorem 1.1. In the present note, we give a short proof of Theorem 1.1, based on the weighted version of the handshaking lemma, which reads as follows.

Theorem 1.2 (The weighted version of the handshaking lemma) Let $f$ be any complex valued function defined on the vertex set of a graph $G$. Then

$$
\sum_{u v \in E(G)}(f(u)+f(v))=\sum_{v \in V(G)} d(v) f(v)
$$

By letting $f(v)=1$ for each vertex $v \in V(G)$ in the above lemma, one can deduce the handshaking lemma.

Corollary 1.3 (The handshaking lemma) For any graph $G$ of size $m$,

$$
\sum_{v \in V(G)} d(v)=2 m
$$

By taking the function $f$ in Theorem 1.2 as

$$
f(v)= \begin{cases}\frac{1}{d(v)}, & \text { if } d(v)>0 \\ 1, & \text { if } d(v)=0\end{cases}
$$

one obtains

Corollary 1.4 For any graph $G$ of order $n$,

$$
\sum_{u v \in E(G)}\left(\frac{1}{d(u)}+\frac{1}{d(v)}\right)=n-n_{0}
$$

where $n_{0}$ is the number of isolated vertices in $G$.

Let $V_{0}$ denote the set of isolated vertices in a graph $G$. Došlic et al. established an identity similar to Theorem 1.2, which reads as follows.

Lemma 1.5 (Došlic et al. [16]) The identity

$$
\sum_{u v \in E(G)}[f(d(u))+f(d(v))]=\sum_{u \in V(G) \backslash V_{0}} d(u) f(d(u))
$$

holds for any graph $G$ and any function $f$. 
Note that Theorem 1.2 is an extension of Lemma 1.5. Although both Corollary 1.4 and the following identity for the first Zagreb index $M_{1}(G)$ (see $[17,18]$ for some recent results on this parameter) of a graph $G$ can also be deduced from Lemma 1.5:

$$
\sum_{u v \in E(G)}(d(u)+d(v))=\sum_{u \in V(G)} d(u)^{2}=M_{1}(G)
$$

there are some which cannot be deduced from Lemma 1.5 but can be deduced from Theorem 1.2. For instance,

$$
\sum_{u v \in E(G)}\left(\xi_{G}(u)+\xi_{G}(v)\right)=\sum_{u \in V(G)} d_{G}(u) \xi_{G}(u)
$$

where $\xi_{G}(u)$ is the eccentricity of $u$ in $G$, i.e., the largest distance between $u$ and any other vertex $v$ of $G$. We remark that

$$
M_{1}^{*}(G)=\sum_{u v \in E(G)}\left(\xi_{G}(u)+\xi_{G}(v)\right)
$$

is defined by Ghorbani and Hosseinzadeh in [19], while the eccentric connectivity index

$$
\xi^{c}(G)=\sum_{u \in V(G)} d_{G}(u) \xi_{G}(u)
$$

is defined by Sharma et al. [20].

Another application of Theorem 1.2 is a new expression of the connective eccentricity index $\xi^{c e}(G)$ of a connected graph $G$, defined by Yu and Feng [21] as

$$
\xi^{c e}(G)=\sum_{v \in V(G)} \frac{d_{G}(v)}{e_{G}(v)}
$$

By Theorem 1.2,

$$
\sum_{u v \in E(G)}\left(\frac{1}{\xi_{G}(u)}+\frac{1}{\left.\xi_{G}(v)\right)}\right)=\sum_{v \in V(G)} \frac{d_{G}(v)}{e_{G}(v)}=\xi^{c e}(G) .
$$

\section{The proofs}

Proof of Theorem 1.2 Every term $f(v)$ occurs $d(v)$ times in the left hand side summation, as it occurs exactly the same times in the right hand side of the identity.

Proof of Theorem 1.1 It is well known that for any two positive real numbers $a$ and $b$, their geometric mean is greater than or equal to their harmonic mean, that is,

$$
\sqrt{a b} \geq \frac{2}{\frac{1}{a}+\frac{1}{b}}
$$

with equality if and only if $a=b$. Therefore, together with Corollary 1.4,

$$
R(G)=\sum_{u v \in E(G)} \frac{1}{\sqrt{d(u) d(v)}} \leq \sum_{u v \in E(G)} \frac{1}{2}\left(\frac{1}{d(u)}+\frac{1}{d(v)}\right)=\frac{n-n_{0}}{2} \leq \frac{n}{2}
$$


where $n_{0}$ is the number of isolated vertices in $G$. If $R(G)=\frac{n}{2}$, we conclude from the above inequalities that $n_{0}=0$ and $d(u)=d(v)$ for any two adjacent vertices $u$ and $v$ in $G$. It follows that $G$ has no isolated vertices and every component of $G$ is regular.

Next assume that $G$ has no isolated vertices, $G_{1}, \ldots, G_{k}$ be all components of $G$, and $G_{i}$ be a $r_{i}$-regular graph of order $n_{i}$ for any $i \in\{1, \ldots, k\}$. Then

$$
R\left(G_{i}\right)=\sum_{u v \in E\left(G_{i}\right)} \frac{1}{\sqrt{d(u) d(v)}}=\sum_{u v \in E\left(G_{i}\right)} \frac{1}{r_{i}}=\frac{\left|E\left(G_{i}\right)\right|}{r_{i}} .
$$

Thus,

$$
R\left(G_{i}\right)=\frac{n_{i} r_{i}}{2} \frac{1}{r_{i}}=\frac{n_{i}}{2}
$$

by the handshaking lemma (Corollary 1.3), whence

$$
R(G)=\sum_{i=1}^{k} R\left(G_{i}\right)=\sum_{i=1}^{k} \frac{n_{i}}{2}=\frac{n}{2} .
$$

\section{Competing interests}

The author declares to have no competing interests.

\section{Acknowledgements}

The author is grateful to the referees for their helpful comments and to Professor Fajtlowicz for kindly sending a copy of 'Written on the Wall, a list of conjectures of Graffiti'. This work was supported by NSFC (No. 11161046).

Received: 19 June 2014 Accepted: 3 September 2014 Published: 16 September 2014

\section{References}

1. Todeschini, R, Consonni, V: Handbook of Molecular Descriptors. Wiley-HCH, Weinheim (2000)

2. Randić, M: On characterization of molecular branching. J. Am. Chem. Soc. 97, 6609-6615 (1975)

3. Li, X, Gutman, I: Mathematical Aspects of Randić-Type Molecular Structure Descriptors. University of Kragujevac, Kragujevac (2006)

4. Li, X, Shi, Y: A survey on the Randić index. MATCH Commun. Math. Comput. Chem. 59, 127-156 (2008)

5. Bozkurt, SB, Güngör, AD, Gutman, I, Çevik, AS: Randić matrix and Randić energy. MATCH Commun. Math. Comput. Chem. 64, 239-250 (2010)

6. Divnić, R, Pavlović, L: Proof of the first part of the conjecture of Aouchiche and Hansen about the Randić index. Discrete Appl. Math. 161, 953-960 (2013)

7. Das, KC, Sorgun, S: On Randić energy of graphs. MATCH Commun. Math. Comput. Chem. 72, 227-238 (2014)

8. Gomes, H, Gutman, I, Martines, EA, Robbiano, M, San Martin, B: On Randić spread. MATCH Commun. Math. Comput. Chem. 72, 249-266 (2014)

9. Liang, M, Liu, B: On the Randić index and girth of graphs. Discrete Appl. Math. 161, $212-216$ (2013)

10. Liu, J: On a conjecture of the Randić index and the minimum degree of graphs. Discrete Appl. Math. 161, 2544-2548 (2013)

11. Su, G, Xiong, L, Su, X: Maximally edge-connected graphs and zeroth-order general Randić index for $0<\alpha<1$. Discrete Appl. Math. 167, 261-268 (2014)

12. Bollobás, B, Erdős, P: Graphs of extremal weights. Ars Comb. 50, 225-533 (1998)

13. Fajtlowicz, S: Written on the Wall, a list of conjectures of Graffiti. Available from the author

14. Caporossi, G, Gutman, I, Hansen, P, Pavlović, L: Graphs with maximum connectivity index. Comput. Biol. Chem. 27 85-90 (2003)

15. Pavlović, L, Gutman, I: Graphs with extremal connectivity index. Novi Sad J. Math. 31, $53-58$ (2001)

16. Došlic, T, Furtula, B, Graovac, A, Gutman, I, Moradi, S, Yarahmadi, Z: On vertex-degree-based molecular structure descriptors. MATCH Commun. Math. Comput. Chem. 66, 613-626 (2011)

17. Hamzeh, A, Reti, T: An analogue of Zagreb index inequality obtained from graph irregularity measures. MATCH Commun. Math. Comput. Chem. 72, 669-684 (2014)

18. Xu, K, Das, KC, Balachandran, S: Maximizing the Zagreb indices of $(n, m)$-graphs. MATCH Commun. Math. Comput. Chem. 72, 641-654 (2014)

19. Ghorbani, M, Hosseinzadeh, MA: A new version of Zagreb indices. Filomat 26(1), 93-100 (2012)

20. Sharma, V, Goswami, R, Madan, AK: Eccentric connectivity index: a novel highly discriminating topological descriptor for structure-property and structure-activity studies. J. Chem. Inf. Comput. Sci. 37, 273-282 (1997)

21. Yu, G, Feng, L: On connective eccentricity index of graphs. MATCH Commun. Math. Comput. Chem. 69, 611-628 (2013) 
doi:10.1186/1029-242X-2014-351

Cite this article as: $\mathrm{Wu}$ : The weighted version of the handshaking lemma with an application. Journal of Inequalities and Applications 2014 2014:351.

Submit your manuscript to a SpringerOpen ${ }^{\circ}$ journal and benefit from:

- Convenient online submission

- Rigorous peer review

- Immediate publication on acceptance

Open access: articles freely available online

- High visibility within the field

- Retaining the copyright to your article

Submit your next manuscript at $\boldsymbol{s p r i n g e r o p e n . c o m ~}$ 